\title{
Surgical ablation of atrial fibrillation trends and outcomes in North America
}

\author{
Niv Ad, MD, ${ }^{\text {a }}$ Rakesh M. Suri, MD, DPhil, ${ }^{\mathrm{b}}$ James S. Gammie, MD, ${ }^{\mathrm{c}}$ Shubin Sheng, PhD ${ }^{\mathrm{d}}$ \\ Sean M. O'Brien, $\mathrm{PhD},{ }^{\mathrm{d}}$ and Linda Henry, $\mathrm{PhD}^{\mathrm{a}}$
}

Objective: Despite growing awareness of the clinical significance of atrial fibrillation (AF) and observational data demonstrating the safety and efficacy of surgical therapy, $\mathrm{AF}$ ablation is variably performed among patients with AF undergoing cardiac surgery. We examined the national trends of surgical ablation and perioperative outcomes for stand-alone surgical ablation of AF.

Methods: Using the Society of Thoracic Surgeons Adult Cardiac Surgery Database, 91,801 (2005-2010) surgical AF ablations were performed of which $4893(5.3 \%)$ were stand-alone procedures. The outcomes of 854 propensity-matched pairs having "on" versus "off" cardiopulmonary bypass stand-alone ablation were compared.

Results: The percentage of patients with preoperative AF increased from 2005 to 2010 (from $10.0 \%$ to $12.2 \%$ ). Overall, $40.6 \%$ of patients with AF underwent concomitant surgical ablation-a significant decline of $1.6 \%$ from 2005 to 2010 . The number of stand-alone surgical ablations increased significantly from 552 to 1041 cases (2005-2010). Overall, the stand-alone group had a mean age of 60 years, $71 \%$ were men, and $80 \%$ were treated "off" cardiopulmonary bypass. The "on" cardiopulmonary bypass group had significantly more pulmonary disease, diabetes, and congestive heart failure. Overall, the operative mortality and stroke rate was $0.7 \%$ for each. After propensity matching, the "off" cardiopulmonary bypass group underwent significantly fewer reoperations for bleeding and had a lower incidence of prolonged ventilation and shorter hospitalization. New pacemaker implantation was low, without group differences.

Conclusions: The prevalence of AF in patients undergoing cardiac surgery has increased, as has the number of stand-alone surgical ablations. The treatment of concomitant disease declined slightly. Isolated surgical ablation is safe, performed "on" or "off" cardiopulmonary bypass. These results support consideration of surgical AF ablation as an alternative to percutaneous ablation for patients with lone AF. (J Thorac Cardiovasc Surg 2012;144:1051-60)

Earn CME credits at

http://cme.ctsnetjournals.org

The surgical treatment of atrial fibrillation (AF), whether as a stand-alone procedure or concomitantly with another cardiac procedure has been performed for more than 2 decades. ${ }^{1}$ The recent introduction of newer surgical ablation devices has resulted in significant expansion of the number of surgical ablation procedures performed nationally owing

\footnotetext{
From the Inova Heart and Vascular Institute, ${ }^{\text {a }}$ Falls Church, Va; Mayo Clinic, ${ }^{\mathrm{b}}$ Rochester, Minn; Division of Cardiac Surgery, ${ }^{\mathrm{c}}$ University of Maryland Medical Center, Baltimore, Md; and Duke Clinical Research Institute, ${ }^{\mathrm{d}}$ Durham, NC.

Disclosures: Authors have nothing to disclose with regard to commercial support.

Read at the 38th Annual Meeting of The Western Thoracic Surgical Association, Maui, Hawaii, June 27-30, 2012.

Received for publication June 29, 2012; accepted for publication July 26, 2012; available ahead of print Aug 23, 2012.

Address for reprints: Niv Ad, MD, Division of Cardiac Surgery, Cardiac Surgery Research, Inova Heart and Vascular Institute, 3300 Gallows Rd, Falls Church, VA 22042 (E-mail: Niv.ad@inova.org).

$0022-5223 / \$ 36.00$

Copyright (c) 2012 by The American Association for Thoracic Surgery

http://dx.doi.org/10.1016/j.jtcvs.2012.07.065
}

to the technical ease and speed of application. ${ }^{2,3}$ Despite a growing awareness of the clinical significance of $\mathrm{AF}$, along with several prospective and observational studies demonstrating the safety and efficacy of surgical ablation early and late after surgery, AF ablation remains variably performed among patients with $\mathrm{AF}$ undergoing cardiac surgery. ${ }^{2,4-7}$ Using the Society of Thoracic Surgeons (STS) Adult Cardiac Surgery Database (ACSD), we sought to assess the national trends for concomitant surgical ablation of $\mathrm{AF}$ for elective, urgent, and nonreoperative cardiac surgery patients and the perioperative clinical outcomes for patients undergoing stand-alone surgical ablation procedures for lone AF with or without the use of cardiopulmonary bypass $(\mathrm{CPB})$.

\section{METHODS \\ Data Source}

The STS has maintained a prospective database of patients undergoing cardiothoracic surgery in the United States since 1987. Harvested data are maintained and analyzed by the Duke Clinical Research Institute in compliance with the Health Insurance Portability and Accountability Act of 1996 Variables are collected on a standardized data form that includes information about patient demographics, medical history, surgical procedures, and outcome (available from: http://www.ctsnet.org/file/ThoracicDCFV2_07_ Nonannotated.pdf). In the present study, we used data from the STS ACSD 


$$
\begin{aligned}
& \text { Abbreviations and Acronyms } \\
& \begin{aligned}
\text { ACSD } & =\text { Adult Cardiac Surgery Database } \\
\text { AF } & =\text { atrial fibrillation } \\
\text { AVR } & =\text { aortic valve replacement } \\
\text { CABG } & =\text { coronary artery bypass grafting } \\
\text { CPB } & =\text { cardiopulmonary bypass } \\
\text { HRS } & =\text { Heart Rhythm Society } \\
\text { ISMICS } & =\text { International Society for Minimally } \\
& \text { Cardiothoracic Surgery } \\
\text { MVR } & =\text { mitral valve repair } \\
\text { STS } & \text { Society of Thoracic Surgeons }
\end{aligned}
\end{aligned}
$$

to report on surgical ablation procedures for AF performed as an isolated procedure or concomitantly with other cardiac surgical procedures from 2005 to 2010. Data related to the specific lesion set and ablative technology were variably collected owing to changes in device technology; therefore, this information was not included in the present report. The new "Surgical Ablation for Atrial Fibrillation" module developed by the STS will theoretically improve the ability to collect meaningful data related to the lesion set and ablative technology (available from: http://www.sts.org/news/sts-atrialfibrillation-module-now-available).

The type of analyses presented in this report have been reviewed and approved by the Duke University Health System institutional review board under protocol number CR1_Pro00005876.

\section{Study Population}

The study population included patients who had undergone surgical ablation for AF either as a stand-alone procedure or concomitantly with other cardiac procedures at STS-participating hospitals between January 1, 2005 and December 31, 2010. Patients were excluded if they met any of the following criteria: missing data regarding CPB status, history of coronary artery bypass grafting (CABG), valve, or other cardiac operation, and emergent or emergent salvage status.

\section{Statistical Analysis}

The distribution of patient characteristics and outcomes was summarized using the median or mean and interquartile range (25th to 75 th percentile) for continuous variables and the percentage distribution for categorical variables. Comparisons of subgroups were performed using Wilcoxon rank sum tests (continuous variables) or $\chi^{2}$ tests (categorical variables).

Propensity scores of CPB usage were estimated using a logistic model that included the following variables: age modeled as linear spline with knots at 50 and 60, gender, body surface area modeled as quadratic polynomial separately for men and women, ejection fraction truncated between $10 \%$ and $50 \%$, nonwhite race, dialysis, cardiogenic shock, hypertension, immunosuppressive treatment, percutaneous coronary intervention within 6 hours, preoperative intra-aortic balloon pump or inotropes, peripheral vascular disease, unstable angina (no myocardial infarction $<7$ days), left main disease, preoperative symptomatic AF within 2 weeks of surgery, $\mathrm{AF}$ correction surgery modeled as a standard surgical maze procedure or a combination of standard and other procedure versus other surgical ablative procedure, cerebrovascular disease or cerebrovascular accident, chronic lung disease, diabetes, number of diseased vessels, timing of myocardial infarction, operative status (elective vs urgent), congestive heart failure, and New York Heart Association class. Missing values were imputed to the most frequent values. Patients were then matched using a Greedy 5 to 1 digit matching algorithm. Standardized differences were used to assess significance in differences of preoperative variables between the 2 groups ("on pump" vs "off pump"). A standardized difference was used, rather than a $P$ value, because it has been shown by others to not be sensitive to the sample size, as the $P$ value is, and hence better for evaluation of propensity matching.

After propensity matching, the postoperative outcomes of the on-CPB and off-CPB groups were compared using McNemar tests (matched comparison) for binary outcomes and Wilcoxon signed-rank tests for continuous outcomes. $P$ values were not adjusted for multiple comparisons. Analysis was performed using SAS, version 9.1 (SAS Institute, Cary, NC).

\section{RESULTS}

\section{Concomitant Surgical Ablation Procedures for AF}

Of the patients undergoing elective or urgent nonredo cardiac surgery in North America during the study period, $11 \%(\mathrm{n}=153,239)$ presented with a history of AF, and 62,152 surgical ablations for concomitant AF were performed (Figure 1). The frequency of concomitant surgical ablations performed between 2005 and 2010 was $40.6 \%$ (Figure 1)and declined during the study period. CABG patients had the lowest incidence of preoperative AF $(6.5 \%)$ and those undergoing mitral valve repair (MVR) the greatest $(29 \%)$. A steady increase in the number of surgical ablation procedures performed annually was documented, with a total of 8461 procedures in 2005 and 11,363 procedures in 2010. However, the overall number of patients presenting for cardiac surgery with AF also increased from 20,878 patients in 2005 to 29,202 patients in 2010 (Figure 1).

An interesting trend in concomitant surgical ablation was identified when the percentage of patients with $\mathrm{AF}$ treated was assessed by the type of concomitant procedure (Figure 2 and Table 1). On average, $61.5 \%$ of patients with preoperative AF undergoing MVR underwent ablation compared with only $27.5 \%$ of patients undergoing CABG. Patients undergoing isolated aortic valve replacement (AVR) with AF underwent ablation $33.9 \%$ of the time. The effect of MVR on the rate of surgical ablation was also documented when analyzing the concomitant CABG plus AVR group of patients. This revealed that the combined AVR + CABG patients with AF underwent surgically ablation on average only $32.1 \%$ of the time and the combined CABG + MVR underwent surgically ablation on average $51.8 \%$ of the time. Detailed data regarding the incidence of AF ablation stratified by year is listed in Table 1.

\section{Stand-Alone Surgical Ablation Procedures}

Demographic data for the group of patients undergoing stand-alone procedures is presented in Table 2. The total of number of stand-alone surgical ablation procedures performed in 375 centers between 2005 and 2010 was 4893. Throughout the study period, the number of stand-alone procedures performed annually almost doubled, from 552 procedures in 2005 to 1014 cases in 2010, using both on- and off-CPB strategies. A total of 


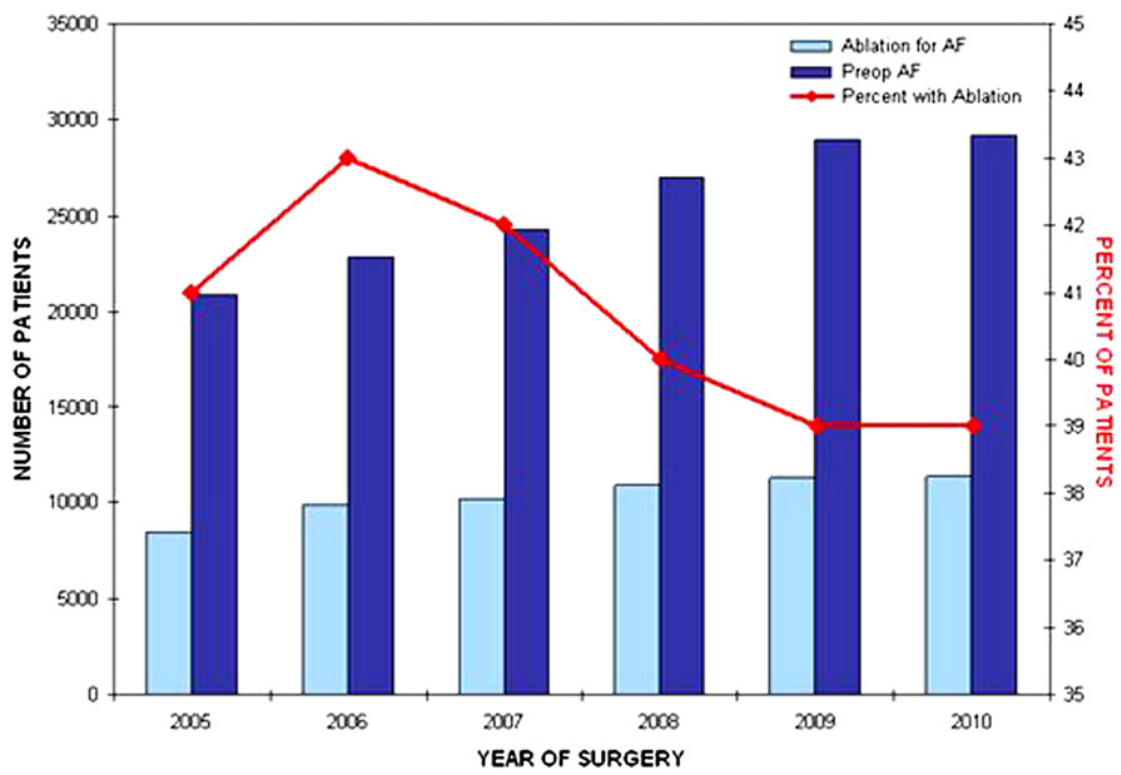

FIGURE 1. Frequency of preoperative (Preop) atrial fibrillation $(A F)$ and surgical ablation for AF procedures among patients undergoing primary nonemergent cardiac surgery.

4449 elective or urgent, nonredo stand-alone procedures were performed, of which $876(20 \%)$ were performed with CPB and $3573(80 \%)$ were performed without CPB. Differences between groups stratified by CPB status are presented in Table 3 . The on-CPB group had a significantly greater body mass index, incidence of diabetes mellitus (insulin and noninsulin dependent), history of smoking, chronic obstructive pulmonary disease, congestive heart failure, and cerebrovascular disease. Patients in the on-CPB group underwent urgent surgery at a rate of $5.94 \%$ versus $0.73 \%$ for the off-CPB group $(P<.0001)$, and the ejection fraction was significantly greater in the off-CPB group $(52.75 \%$ vs $55.59 \%, P<.0001)$.

The uncorrected outcomes after stand-alone surgical ablation are presented in Table 3. The overall operative mortality (30 days) was $0.74 \%$ (off-CPB group, $0.5 \%$; on-CPB group, $1.7 \% ; P=.7)$. The rate of any STS complication was $16.43 \%$, with significantly greater rates for the

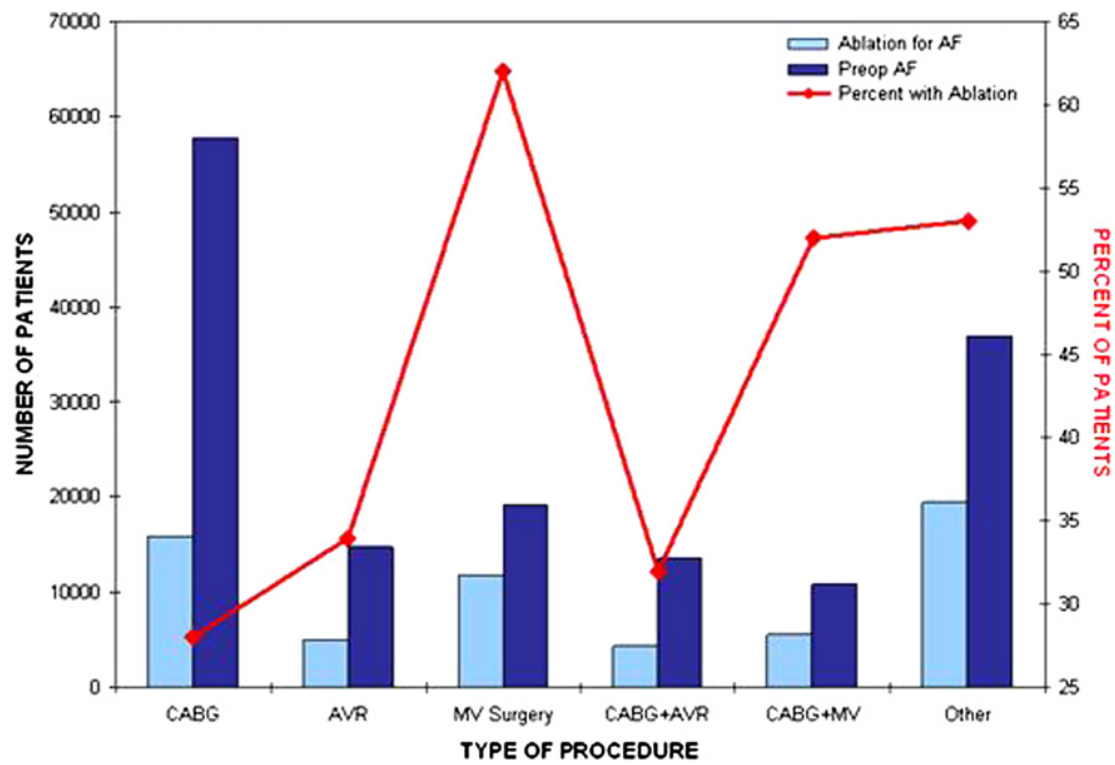

FIGURE 2. Concomitant surgical ablation for atrial fibrillation $(A F)$ by type of concomitant procedure. Preop, Preoperative; $C A B G$, coronary bypass grafting; $A V R$, aortic valve replacement; $M V$, mitral valve; Other, left ventricular aneurysm repair, ventricular septal defect repair, atrial septal defect repair, batista, surgical ventricular restoration, congenital defect repair, transmyocardial laser revascularization, cardiac trauma, cardiac transplant, aortic aneurysm, other. 
TABLE 1. Percentage of concomitant surgical ablation for atrial fibrillation performed for different concomitant procedure types

\begin{tabular}{lcccccc}
\hline $\begin{array}{c}\text { Concomitant } \\
\text { procedure }\end{array}$ & $\begin{array}{c}\mathbf{2 0 0 5} \\
\mathbf{( \% )}\end{array}$ & $\begin{array}{c}\mathbf{2 0 0 6} \\
\mathbf{( \% )}\end{array}$ & $\begin{array}{c}\mathbf{2 0 0 7} \\
\mathbf{( \% )}\end{array}$ & $\begin{array}{c}\mathbf{2 0 0 8} \\
\mathbf{( \% )}\end{array}$ & $\begin{array}{c}\mathbf{2 0 0 9} \\
\mathbf{( \% )}\end{array}$ & $\begin{array}{c}\mathbf{2 0 1 0} \\
\mathbf{( \% )}\end{array}$ \\
\hline CABG & 26 & 30 & 28 & 28 & 27 & 26 \\
AVR & 33 & 36 & 36 & 35 & 34 & 31 \\
MVR & 61 & 64 & 62 & 62 & 60 & 60 \\
CABG + AVR & 32 & 34 & 36 & 33 & 30 & 30 \\
CABG + MV & 54 & 53 & 52 & 51 & 50 & 51 \\
Other & 55 & 57 & 55 & 51 & 49 & 50 \\
\hline
\end{tabular}

$C A B G$, Coronary bypass grafting; $A V R$, aortic valve replacement; $M V R$, mitral valve repair; Other, left ventricular aneurysm repair, ventricular septal defect repair, atrial septal defect repair, batista, surgical ventricular restoration, congenital defect repair, transmyocardial laser revascularization, cardiac trauma, cardiac transplant, aortic aneurysm, other.

on-CPB group (27.97\% vs $13.60 \%, P<.0001)$. The overall stroke rate was $0.72 \%$, with a significantly greater incidence for the on-CPB group at $1.26 \%(P=.017)$. The renal failure rates were greater for the on-CPB group, with an overall incidence of $2.45 \% \quad(5.48 \%$ vs $1.71 \%$; $P=.0001)$. The incidence of blood transfusion was greater for the on-CPB group at $17.6 \%$ (vs $3.1 \%$ off-CPB,
$P<.001)$. The median hospital stay was 6 days in the onCPB group and 4 days in the off-CPB group $(P<.0001)$. The newly implanted pacemaker rate was similar for both groups, with an overall rate of $1 \%(P=.1686)$.

After the identification of 854 matched pairs, a propensity analysis was performed $(\mathrm{n}=1708$; Table 4 and Figures 3 and 4). The perioperative results for the matched-group patients demonstrated no significant differences between the groups for all major outcomes, except for prolonged intubation ( $>24$ hours; $6.56 \%$ vs $3.98 \%$ for on-CPB and off-CPB groups, respectively; $P=.014$ ) and reoperation for bleeding $(2.2 \%$ vs $0.35 \%$ for on-CPB and off-CPB group, respectively; $P=.0003$ ). The median length of stay remained significantly longer for the on-CPB group than for the off-CPB in the matched population (6 vs 4 days, respectively; $P<.001$ ) (Table 5).

\section{DISCUSSION}

In the present study, data from the STS ACSD was used to describe contemporary practice of surgical AF ablation in North America between 2005 and 2010. The data included surgical ablation performed as a stand-alone procedure or

TABLE 2. Patient demographics and risk factors

\begin{tabular}{|c|c|c|c|c|}
\hline Variable & Overall $(n=4449)$ & On-CPB $(n=876)$ & Off-CPB $(n=3573)$ & $P$ value* \\
\hline \multicolumn{5}{|l|}{ Demographics } \\
\hline Age† (y) & & & & .4074 \\
\hline Mean & 60.42 & 59.42 & 60.67 & \\
\hline IQR & $54-68$ & $53-67$ & $54-68$ & \\
\hline Men & 71.00 & 71.92 & 70.78 & .1924 \\
\hline \multicolumn{5}{|l|}{ Risk factors } \\
\hline Weight $(\mathrm{kg}) \dagger$ & & & & .0009 \\
\hline Mean & 96.46 & 98.65 & 95.93 & \\
\hline IQR & $81.55-109.00$ & $83-113$ & $81-108.6$ & \\
\hline Body surface area $\dagger\left(\mathrm{m}^{2}\right)$ & & & & .0036 \\
\hline Mean & 2.12 & 2.14 & 2.12 & \\
\hline IQR & $1.95-2.3$ & $1.96-2.32$ & $1.94-2.29$ & \\
\hline Smoker (any form of past tobacco use) & 23.51 & 24.66 & 23.23 & .0419 \\
\hline Preoperative AF & 91.71 & 89.73 & 92.19 & .7363 \\
\hline Diabetes mellitus & 14.46 & 17.94 & 13.61 & .0056 \\
\hline Renal failure & 0.65 & 0.68 & 0.64 & .5504 \\
\hline Preoperative dialysis & 0.34 & 0.34 & 0.34 & .6151 \\
\hline Hypertension & 61.18 & 62.21 & 60.93 & .1200 \\
\hline Chronic lung disease/COPD & 12.29 & 16.78 & 11.20 & .0242 \\
\hline Peripheral vascular disease & 3.28 & 4.00 & 3.11 & .2303 \\
\hline Cerebrovascular disease & 10.90 & 13.36 & 10.30 & .5950 \\
\hline Preoperative MI within $21 \mathrm{~d}$ & 0.22 & 0.68 & 0.11 & .0174 \\
\hline Preoperative $\mathrm{CHF}$ & 9.69 & 19.86 & 7.19 & $<.0001$ \\
\hline CHF-NYHA class 4 & 0.63 & 1.48 & 0.42 & $<.0001$ \\
\hline Ejection fraction $\dagger$ & & & & $<.0001$ \\
\hline Mean & 54.94 & 52.75 & 55.59 & \\
\hline IQR & $50-60$ & $50-60$ & $50-60$ & \\
\hline Urgent procedure status & 1.75 & 5.94 & 0.73 & $<.0001$ \\
\hline
\end{tabular}

Data presented as mean and IQR or percentages. $C P B$, Cardiopulmonary bypass; $I Q R$, interquartile range; $A F$, atrial fibrillation; $C O P D$, chronic obstructive pulmonary disease; $M I$, myocardial infarction; $C H F$, congestive heart failure; $N Y H A$, New York Heart Association. $* P$ values based on stratum-adjusted Pearson $\chi^{2}$ tests for all categorical row variables. $\dagger$ P values based on stratum-adjusted $\chi^{2}$ rank-based group mean score statistics for all continuous/ordinal row variables. 
TABLE 3. Surgical outcomes after surgical ablation for atrial fibrillation 2005-2010: unmatched data

\begin{tabular}{|c|c|c|c|c|}
\hline Outcome & Overall $(n=4449$ & On-CPB $(n=876)$ & Off-CPB $(n=3573)$ & $P$ value* \\
\hline Operative mortality & 0.74 & 1.71 & 0.50 & .7036 \\
\hline Stroke & 0.72 & 1.26 & 0.59 & .0176 \\
\hline Renal failure & 2.45 & 5.48 & 1.71 & .0001 \\
\hline New pacemaker & 1.03 & 0.80 & 1.09 & .1686 \\
\hline Any complications & 16.43 & 27.97 & 13.60 & $<.0001$ \\
\hline Perioperative AF & 1.55 & 3.20 & 1.15 & .8025 \\
\hline Deep sternum infection & 0.04 & 0.23 & 0.00 & .0132 \\
\hline Reoperation for bleeding/tamponade & 0.99 & 2.28 & 0.67 & .0127 \\
\hline Pneumonia & 1.66 & 2.74 & 1.40 & .6512 \\
\hline Prolonged ventilation ( $>24$ h) & 3.51 & 6.96 & 2.66 & .1279 \\
\hline Total ventilation duration $\dagger(\mathrm{h})$ & & & & $<.0001$ \\
\hline Median & 3.45 & 5.40 & 1.40 & \\
\hline $\mathrm{IQR}$ & $0-7.12$ & $3.45-9.70$ & $0-5.25$ & \\
\hline Postoperative ICU stay $\dagger$ (h) & & & & $<.0001$ \\
\hline Median & 26 & 31.15 & 25 & \\
\hline IQR & $21-49$ & $23-70.30$ & $20.05-47$ & \\
\hline Readmission $\leq 30 \mathrm{~d}$ & 11.22 & 10.73 & 11.34 & .5551 \\
\hline Intraoperative blood products transfused & 5.96 & 17.58 & 3.11 & $<.0001$ \\
\hline Discharge medication (warfarin) & 75.88 & 74.43 & 76.24 & .0672 \\
\hline Total length of stay $(\mathrm{d}) \dagger$ & & & & $<.0001$ \\
\hline Median & 4 & 6 & 4 & \\
\hline IQR & $3-6$ & $5-9$ & $3-6$ & \\
\hline
\end{tabular}

concomitantly with another cardiac surgical procedure. The findings of our study suggest that in contrast to a previous report by Gammie and colleagues, ${ }^{2}$ no significant change in the rate of surgical ablation for AF was documented for concomitant procedure with a use of surgical correction for $\mathrm{AF}$ of $39 \%$ to $43 \%$ in nonredo, nonemergent patients. During the study period, 4893 stand-alone procedures were performed. Most $(80 \%)$ were performed without the use of CPB. The data showed excellent safety for both techniques.

\section{Concomitant Surgical Ablation Procedures}

Concomitant surgical ablation for AF is routinely performed in North America; however, there is variability among cardiac surgeons and centers in the rate these procedures are performed. In an attempt to eliminate variables that could affect the decision to perform surgical ablation because of surgical complexity, we excluded patients who had undergone surgery as redo cardiac surgery or had required emergent surgery (ie, emergent, emergent salvage, cardiogenic shock).

The percentage of patients with a history of AF captured in present study was $11 \%$, similar to that reported by Gammie and colleagues. ${ }^{2}$ The greatest rates were documented for patients undergoing MVR, with lower rates of preoperative $\mathrm{AF}$ captured for patients with coronary artery disease undergoing $\mathrm{CABG}$. Although surgical ablation as a concomitant procedure is routinely performed, a noted difference was seen in the rate surgical ablations were performed for the different types of concomitant procedures, with more than $60 \%$ of patients undergoing MVR also receiving ablation, but only about $30 \%$ of patients undergoing CABG or AVR also receiving surgical correction of AF. The variability between procedures is probably related to access to the left atrium and concerns related to efficacy and increased morbidity related to the added procedure.

The Heart Rhythm Society (HRS) guidelines ${ }^{8,9}$ published consensus indications for concomitant surgical ablation. A IIA indication (level $\mathrm{C}$ evidence) was recommended for symptomatic patients with all types of AF and a failed class 1 or 3 antiarrhythmic drug. The same recommendation was given to patients with paroxysmal and persistent AF that did not fail antiarrhythmic treatment, with an IIB indication (level $\mathrm{C}$ evidence) for patients with long-term persistent AF.

In 2010, the International Society for Minimally Cardiothoracic Surgery (ISMICS), published a detailed consensus statement, ${ }^{7}$ in which a set of recommendations was given. In concomitant procedures, a class I (level A evidence) was given to the efficacy of surgical ablation for AF in restoring sinus rhythm both short and long term. It was also found that surgical ablation is associated with an increased ejection fraction and improved exercise tolerance test, class IIA (level A evidence), and a reduced risk of stroke and thromboembolic events and increased long-term survival, class IIA (level B evidence). The statement also found that concomitant surgery was not associated with an 
TABLE 4. Distribution of baseline patient characteristics and outcomes-matched groups

\begin{tabular}{|c|c|c|c|c|}
\hline Variable & Overall $(n=1708)$ & On-CPB $(n=854)$ & Off-CPB $(n=854)$ & $P$ value* \\
\hline \multicolumn{5}{|l|}{ Demographics } \\
\hline Age† (y) & & & & .4568 \\
\hline Mean & 59.59 & 59.48 & 59.71 & \\
\hline IQR & $53-67$ & $53-67$ & $53-67$ & \\
\hline Men & 70.90 & 71.90 & 69.91 & .3653 \\
\hline \multicolumn{5}{|l|}{ Risk factors } \\
\hline Body surface area $\nmid\left(\mathrm{m}^{2}\right)$ & & & & .3486 \\
\hline Mean & 0.33 & 0.34 & 0.33 & \\
\hline IQR & $0.16-0.52$ & $0.17-0.52$ & $0.16-0.51$ & \\
\hline Diabetes & 17.56 & 17.92 & 17.21 & .8906 \\
\hline Hypertension & 62.30 & 61.83 & 62.76 & .6897 \\
\hline Peripheral vascular disease & 4.10 & 3.86 & 4.33 & .6255 \\
\hline Cerebrovascular disease & 13.76 & 13.00 & 14.52 & .5618 \\
\hline CHF-NYHA class 4 & 0.88 & 1.05 & 0.70 & .6183 \\
\hline Preoperative MI within $21 \mathrm{~d}$ & 0.35 & 0.35 & 0.35 & 1.0000 \\
\hline Preoperative IABP or inotropes & 1.35 & 1.29 & 1.41 & .8338 \\
\hline Unstable angina without recent $\mathrm{MI}$ & 0.35 & 0.59 & 0.12 & .1020 \\
\hline Three diseased coronary vessels & 3.28 & 3.63 & 2.93 & .6598 \\
\hline Urgent status of procedure & 3.40 & 3.98 & 2.81 & .1817 \\
\hline Preoperative AF & 36.18 & 37.70 & 34.66 & .1906 \\
\hline Ejection fraction $\dagger$ & & & & .6985 \\
\hline Mean & 47.26 & 47.32 & 47.20 & \\
\hline IQR & $50-50$ & $50-50$ & $50-50$ & \\
\hline
\end{tabular}

Data presented as mean and IQR or percentages. $C P B$, Cardiopulmonary disease; $I Q R$, interquartile range; $C H F$, congestive heart failure; $N Y H A$, New York Heart Association; $I A B P$, intra-aortic balloon pump; $M I$, myocardial infarction; $A F$, atrial fibrillation. $* P$ values based on Pearson $\chi^{2}$ tests for all categorical row variables. $\dagger P$ values based on $\chi^{2}$ rankbased group mean score statistics for all continuous/ordinal row variables.

increased risk of operative mortality (level A evidence) and other perioperative complications, including the need for a new pacemaker. Both the HRS guidelines and the ISMICS consensus statements are very important documents, because they agree on the efficacy and safety of the procedures. Surgeons should be aware of these publications when considering the risks and benefits of concomitant surgical ablation procedures.

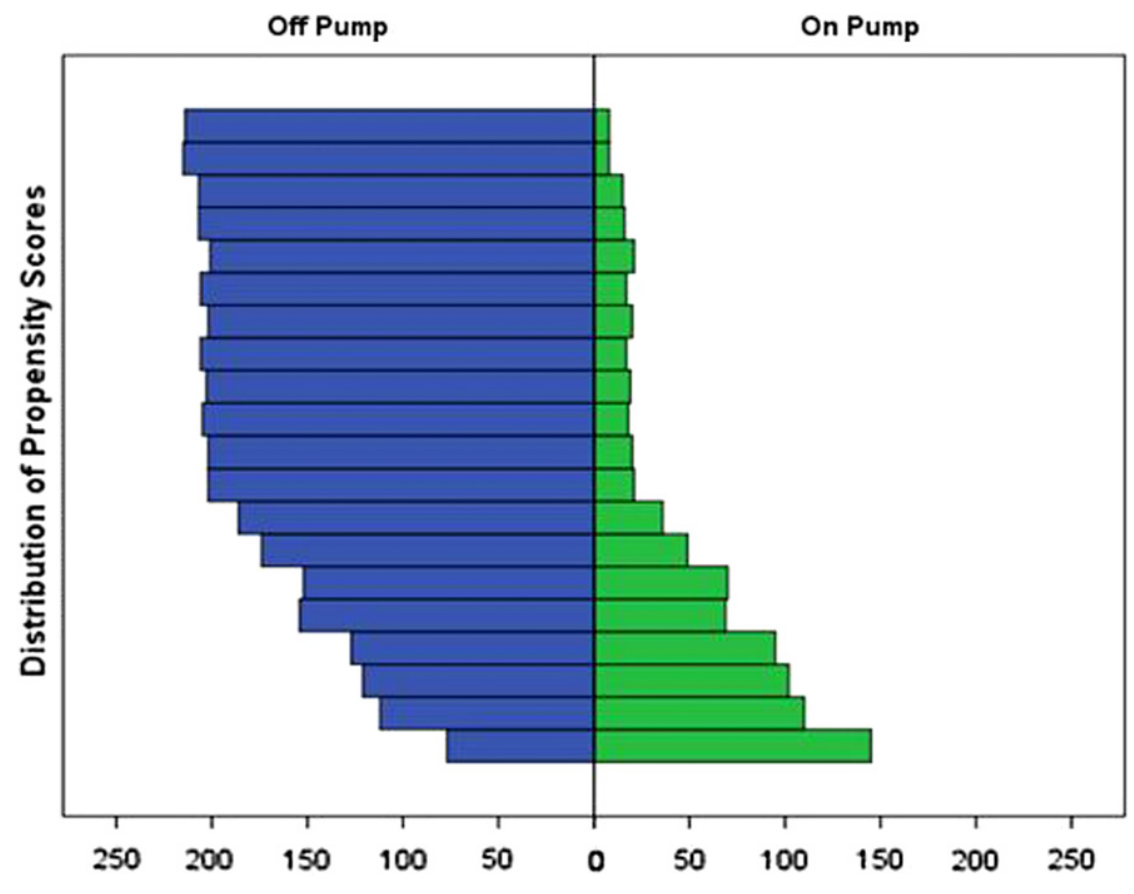

FIGURE 3. Distribution of propensity score percentiles before matching. 


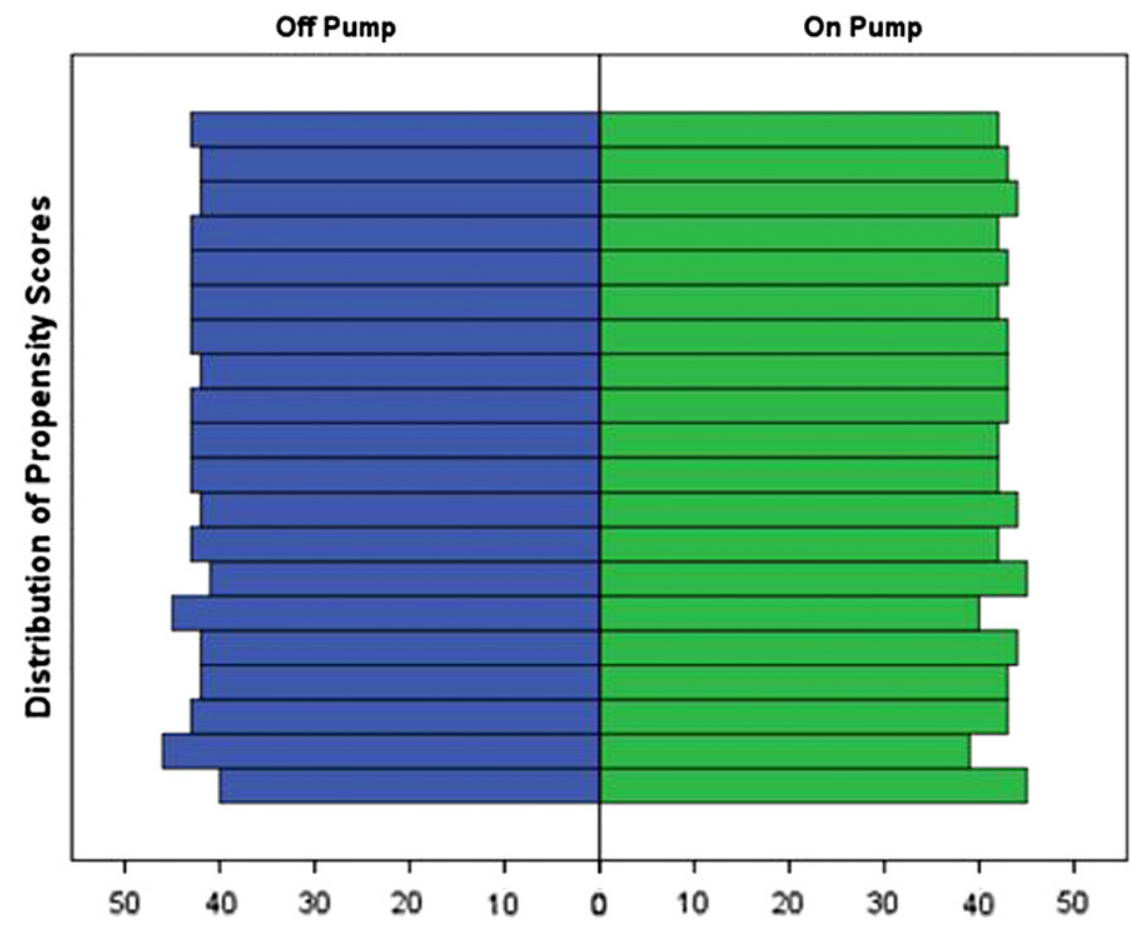

FIGURE 4. Distribution of propensity score percentiles after matching.

A significant history of AF in patients undergoing cardiac surgery was an important predictor of mortality both early and late after surgery. ${ }^{5,6,10}$ In several recent publications, it was shown that surgical correction of AF was not associated with increased operative mortality or morbidity, even in high-risk patients. ${ }^{11-14}$ However, some investigators have found that improved long-term survival was noted compared with patients whose AF was not treated. ${ }^{6,15}$ Others have found equal long-term survival compared with patients who presented for surgery in sinus rhythm. ${ }^{13,14}$

This relatively new evidence should be reviewed in light of the increased risk of thromboembolic events and bleeding events secondary to the use of warfarin therapy. ${ }^{6}$ A significant decrease in the stroke rate was documented in patients after the Cox-maze procedure. ${ }^{16,17}$ The high success rate of surgical ablation, together with appropriate management of the left atrial appendage, has improved our ability to discontinue anticoagulation treatment in most patients after the Cox-maze procedure. This has been found to be unrelated to patients' CHADS score and is an important benefit when considering adding surgical ablation for $\mathrm{AF}^{18}$

When assessing the penetration rate of surgical ablation for AF during concomitant procedures, it is clear that the

TABLE 5. Patient outcomes-matched groups

\begin{tabular}{|c|c|c|c|c|}
\hline Outcome & Overall $(n=1708)$ & On-CPB $(n=854)$ & Off-CPB $(n=854)$ & $P$ value* \\
\hline Operative mortality $(\%)$ & 1.23 & 1.52 & 0.94 & .2752 \\
\hline Stroke $(\%)$ & 1.00 & 1.29 & 0.70 & .2253 \\
\hline Dialysis, newly required $(\%)$ & 0.76 & 1.05 & 0.47 & .1655 \\
\hline New pacemaker $(\%)$ & 1.29 & 0.82 & 1.76 & .0881 \\
\hline Perioperative AF $(\%)$ & 2.46 & 3.04 & 1.87 & .1228 \\
\hline Gastrointestinal complication (\%) & 0.88 & 1.05 & 0.70 & .4386 \\
\hline Prolonged ventilation $(>24 \mathrm{~h})(\%)$ & 5.27 & 6.56 & 3.98 & .0139 \\
\hline Reoperation for bleeding/tamponade (\%) & 1.29 & 2.22 & 0.35 & .0003 \\
\hline Discharge medication (warfarin) $(\%)$ & 74.53 & 73.89 & 75.18 & .5367 \\
\hline Total length of stay (d) & & & & $<.0001$ \\
\hline Median & 5 & 6 & 4 & \\
\hline IQR & $4-8$ & $5-9$ & $3-6$ & \\
\hline
\end{tabular}

$C P B$, Cardiopulmonary bypass; $A F$, atrial fibrillation; $I Q R$, interquartile range. $* P$ values based on McNemar's tests for categorical outcomes and Wilcoxon signed rank tests for continuous outcomes. 
type of the procedure plays an important role in the decision to perform surgical ablation. The data presented in the present study have demonstrated that fewer than $30 \%$ of the patients undergoing CABG are treated and only slightly more than $30 \%$ of patients undergoing AVR also receive ablation (Figure 2, Table 1). However, for surgery involving the mitral valve, more than $60 \%$ of the patients also underwent ablation when only the mitral valve was treated and more than $50 \%$ of the patients did so when MVR was combined with CABG. From these data, we can assume that the addition of left atrial atriotomy is a major negative factor in the decision making of the surgeon, because of perception that added atriotomies could be associated with increased operative risk. Recently published data might contradict this assumption, because it has been demonstrated that in patients requiring CABG or AVR who undergo a Cox-maze procedure, no increased morbidity and mortality was captured. ${ }^{14}$ It might be that surgeons are reluctant to perform such an extensive lesion set that might be required for patients with nonparoxysmal AF. However, this assumption could not be tested in the present study owing to the inherent limitations of the STS ACSD.

The results of the present study suggest that a significant number of patients are not being treated for $\mathrm{AF}$ at cardiac surgery. The HRS guidelines ${ }^{8,9}$ and the ISMICS consensus statement ${ }^{7}$ both clearly recommend performing surgical ablation at surgery in appropriate patients. Education and training on the importance and different techniques of surgical ablation for AF is very important to improve patient care. We also need to improve the evidence of concomitant surgical ablation for AF by conducting more well-controlled and balanced prospective randomized studies.

\section{Stand-Alone Surgical Ablation Procedures}

This is the first report using the STS ACSD focusing on the growth of stand-alone surgical ablation for AF and the perioperative outcomes of such procedures. During the study period, a significant increase in the number of stand-alone procedure with more than 1000 cases performed in 2010. Most stand-alone procedures were performed without the use of $\mathrm{CPB}$ and probably using minimally invasive techniques, such as small thoracotomy or video-assisted approaches. ${ }^{19,20}$

In the recent HRS guidelines, ${ }^{8,9} \mathrm{a}$ IIb (level $\mathrm{C}$ evidence) recommendation was made to consider stand-alone surgical ablation for all types of AF whether or not the patients had undergone previous attempts at catheter ablation. These recommendations are very important because stand-alone surgical ablation was again recognized as a treatment option for AF. It is important, however, to recognize that the same guidelines were much more supportive of percutaneous catheter ablation, with a class I to class IIB indication for all types of AF-associated conditions.
In the present study, we did not attempt to discuss the long-term success rate of surgical ablation, because the STS ACSD was not designed to answer such questions. However, the data provide us with an excellent opportunity to discuss the safety of stand-alone surgical ablation. The ACSD is also very limited in helping us to understand the exact the lesion pattern used during the procedures, because it was not predefined such that would require surgeons to report accurately on every lesion treated and the ablative technology used for the different lesions. If the new STS surgical ablation for AF module is going to gain popularity, such important and unique data should be available in the near future (available from: http://www.sts.org/news/stsatrial-fibrillation-module-now-available). It is obvious, however, that in contrast to off-CPB procedures in which most lesions were confined to the left atrium, in most stand-alone surgical ablation procedures performed using on-CPB techniques, a biatrial lesion set was applied (Table 5). This could have implications regarding the long-term success rate. ${ }^{21}$

The outcome of stand-alone surgical ablation for AF is encouraging. It is also very important to recognize that off-CPB surgical ablation techniques were introduced only recently; therefore, the effect of a surgical learning curve should be considered. The mortality and stroke rates were about $0.7 \%$, and the rate for a newly required pacemaker was $1 \%$. The median length of hospital stay was 4 days, with a relatively low readmission rate at 30 days. It is clear that compared with catheter ablation for $\mathrm{AF}$, the complication rate was higher. However, patients undergoing percutaneous catheter ablation for atrial ablation have had a much lower success rate, exposing patients to additional risk when undergoing the procedure the second, third, and fourth or more times. $^{22,23}$ In a recent report, the complication rate for catheter ablation was not negligible. Procedural complications have been reported to affect $1 \%$ to $8 \%$ of patients undergoing catheter ablation in experienced academic centers ${ }^{23,24}$ and $7 \%$ to $10 \%$ of Medicare patients. ${ }^{25}$ In another report from California, it was shown that patient complications occurred in $5.1 \%$, with 30-day mortality of $0.2 \%$ and a 30 -day stroke/transient ischemic attack rate of $0.76 \%{ }^{26}$ The study from California is important because it compared different types of centers and operator experience across the state, not just the best practices.

Patients who underwent surgery using the heart-lung machine were found to have more comorbidities (Table 2). This was reflected in the patient outcomes in the nonmatched analysis. After the propensity match analysis, which included 1708 patients, the safety of the procedures using CPB was comparable to the safety of those using off-CPB techniques, with only the duration of ventilation, reoperation for bleeding, and length of stay significantly 
better for the off-CPB group. Our experience, and that of others, suggests very low morbidity when performing a full Cox-maze procedure for stand-alone AF, suggesting that the learning curve and experience of the center could have some affect on the morbidity rate. ${ }^{27-29}$

\section{Study Limitations}

The present study used data from the STS ACSD; thus, it was impossible to describe and assess data related to any specific association among lesion set, technology, and outcome. The potential effect of surgeon experience on the rate of performing concomitant surgical ablation procedures also could not be assessed.

\section{CONCLUSIONS}

The present report has demonstrated that surgical ablation for $\mathrm{AF}$ as a concomitant procedure is performed in $40 \%$ of the patients who present to cardiac surgery with a history of AF. This rate is somewhat stable compared with previous report using the same data source. ${ }^{2}$ However, the number of patients presenting with AF has actually increased, which has led to a small decrease in the percentage of patients undergoing a concomitant surgical ablation procedure. This has occurred despite recent publications and guidelines suggesting that surgical ablation for $\mathrm{AF}$ is safe and effective and should be favorably considered. ${ }^{1,6-9,11-14}$

In the present study, we also report on a significant increase in the number of stand-alone surgical ablation procedures. The periprocedural outcomes were encouraging, especially when the significant effect of a learning curve should be expected. Many of the techniques and devices have been newly introduced for procedures performed with or without the use of CPB. Surgeons should also be aware that major limitations still exist for percutaneous catheter ablation and need to assist in elevating the discussion about a team approach to deliver better care for patients with AF.

\section{References}

1. Damiano RJ Jr, Gaynor SL, Bailey M, Prasad S, Cox JL, Boineau JP, et al. The long term outcome of patients with coronary disease and atrial fibrillation undergoing the Cox Maze procedure. J Thorac Cardiovasc Surg. 2003; 126:2016-21

2. Gammie JS, Haddad M, Milford-Beland S, Welke KF, Ferguson TB Jr, O'Brean SM, et al. Atrial fibrillation correction surgery: Lessons from the Society of Thoracic Surgeons national cardiac database. Ann Thorac Surg. 2008;85: 909-15.

3. Viola N, Williams MR, Oz MC, Ad N. The technology in use for the surgical ablation of atrial fibrillation. Semin Thorac Cardiovasc Surg. 2002;14:198-205.

4. Ad N, Barnett SD, Haan CK, O'Brien SM, Milford-Beland S, Speir AM. Does preoperative atrial fibrillation increase the risk for mortality and morbidity after coronary artery bypass grafting? J Thorac Cardiovasc Surg. 2009;137:901-6.

5. Ngaage DL, Schaff HV, Mullany CJ, Barnes S, Dearani JA, Daly RC, Orszulak TA, et al. Does preoperative atrial fibrillation influence early and late outcome of coronary artery bypass grafting? J Thorac Cardiovasc Surg. 2007; 133:182-9.
6. Attaran S, Saleh HZ, Shaw M, Ward A, Pullan M, Fabri BM. Does the outcome improve after radiofrequency ablation for atrial fibrillation in patients undergoing cardiac surgery? A propensity-matched comparison. Eur J Cardiothorac Surg. 2012;41:806-10.

7. Ad N, Cheng DCH, Martin J, et al. Surgical ablation for atrial fibrillation in cardiac surgery: a consensus statement of the International Society of Minimally Invasive Cardiothoracic Surgery (ISMICS) 2009. Innovations. 2010;5:74-83.

8. A report of the Heart Rhythm Society (HRS) Task Force on Catheter Ablation of Atrial Fibrillation developed in partnership with European Heart Rhythm Association (EHRA) and the European Cardiac Arrhythmia (ECAS); in collaboration with the American College of Cardiology (ACC), American Heart Association (AHA), and the Society of Thoracic Surgeons (STS). HRS/ EHRA/ECAS Expert consensus statement on catheter and Cox- Maze III/ IV procedure of atrial fibrillation: recommendations for personnel, policy, procedures and follow-up. Europace. 2007;9:330-79.

9. Calkins H, Kuck KH, Cappato R, Brugada J, Camm AJ, Chen SA, et al. Heart Rhythm Society Task Force on Catheter and Surgical Ablation of Atrial Fibrillation. 2012 HRS/EHRA/ECAS expert consensus statement on catheter and surgical ablation of atrial fibrillation: recommendations for patient selection, procedural techniques, patient management and follow-up, definitions, endpoints, and research trial design: a report of the Heart Rhythm Society (HRS) Task Force on Catheter and Surgical Ablation of Atrial Fibrillation. Developed in partnership with the European Heart Rhythm Association (EHRA), a registered branch of the European Society of Cardiology (ESC) and the European Cardiac Arrhythmia Society (ECAS); and in collaboration with the American College of Cardiology (ACC), American Heart Association (AHA), the Asia Pacific Heart Rhythm Society (APHRS), and the Society of Thoracic Surgeons (STS). Endorsed by the governing bodies of the American College of Cardiology Foundation, the American Heart Association, the European Cardiac Arrhythmia Society, the European Heart Rhythm Association, the Society of Thoracic Surgeons, the Asia Pacific Heart Rhythm Society, and the Heart Rhythm Society. Heart Rhythm. 2012;9:632-96.

10. Ngaage DL, Schaff HV, Barnes SA, Sundt TM, Mullany CJ, Dearani JA, et al. Prognostic implications of preoperative atrial fibrillation in patients undergoing aortic valve replacement: is there an argument for concomitant arrhythmia surgery? Ann Thorac Surg. 2006;82:1392-9.

11. Ad N, Henry L, Hunt S, Holmes SD, Halpin L. The results of the Cox-maze III/IV procedure in patients over 75 years old who present for cardiac surgery with a history of atrial fibrillation. Ann Thorac Surg. 2012;93:1897-904.

12. Ad N, Henry L, Hunt S. The impact of surgical ablation in patients with low ejection fraction, heart failure, and atrial fibrillation. Eur J Cardiothorac Surg. 2011; 40:70-6.

13. Ad N, Henry L, Holmes S, Hunt S. The impact of surgical ablation for atrial fibrillation in high risk patients. Ann Thoracic Surg. 2012;93:1897-904.

14. Ad N, Henry L, Hunt S, Holmes SD. Do we increase the operative risk by adding the Cox maze III procedure to aortic valve replacement and coronary artery bypass surgery? J Thorac Cardiovasc Surg. 2012;143:936-44.

15. Quader MA, McCarthy PM, Gillinov AM, Alster JM, Cosgrove DM III, Lytle BW, et al. Does preoperative atrial fibrillation reduce survival after coronary artery bypass grating? Ann Thorac Surg. 2004;77:1514-22.

16. Ad N, Cox JL, Palazzo T, Kim YD, Syderhoud JP, Degroot KW, et al. Stroke prevention as an indication for the maze procedure in the treatment of atrial fibrillation. Semin Thorac Cardiovasc Surg. 2000;12:56-62.

17. Bando K, Kobayashi J, Hirata M, Satoh T, Niwaya K, Tagusari O, et al. Early and late stroke after mitral valve replacement with a mechanical prosthesis: risk factor analysis of a 24 years' experience. J Thorac Cardiovasc Surg. 2003; 126:358-64.

18. Ad N, Henry L, Schlauch K, Holmes SD, Hunt S. The CHADS score role in managing anticoagulation after surgical ablation for atrial fibrillation. Ann Thorac Surg. 2010;90:1257-62.

19. Wolf RK, Schneeberger EW, Osterday R, Miller D, Merrill W, Flege JB Jr, Gillinov AM. Video-assisted bilateral pulmonary vein isolation and left atrial appendage exclusion for atrial fibrillation. J Thorac Cardiovasc Surg. 2005;130: 797-802.

20. Driessen AH, Krul SP, de Mol BA, de Groot JR. Second chance for a totally thoracoscopic video-assisted pulmonary vein isolation for atrial fibrillation. Ann Thorac Surg. 2012;93:2051-3.

21. Barnett $S$, Ad N. Surgical ablation as treatment for the elimination of atrial fibrillation: a meta-analysis. J Thorac Cardiovasc Surg. 2006;131:1029-35. 
22. Boersma LV, Castella M, van Boven W, Berruezo A, Yilmaz A, Nadal M, et al. Atrial fibrillation catheter ablation versus surgical ablation treatment (FAST): a 2-center randomized clinical trial. Circulation. 2012;125:23-30.

23. Weerasooriya R, Khairy P, Litalien J, Macle L, Hocini M, Sacher F, et al. Catheter ablation for atrial fibrillation: are results maintained at 5 years follow-up? J Am Coll Cardiol. 2011;57:160-6.

24. Cappato R, Calkins H, Chen S-A. Worldwide survey on the methods, efficacy, and safety of catheter ablation for human atrial fibrillation. Circulation. 2005; 111:1100-5.

25. Ellis ER, Culler SD, Simon AW, Reynolds MR. Trends in utilization and complications of catheter ablation for atrial fibrillation in Medicare beneficiaries. Heart Rhythm. 2009;6:1267-73.
26. Shah RU, Freeman JV, Shilane D, Wang PJ, Go AS, Hlatky MA. Procedural complications, rehospitalizations, and repeat procedures after catheter ablation for atrial fibrillation. J Am Coll Cardiol. 2012;59:143-9.

27. Weimar T, Bailey MS, Watanabe Y, Marin D, Maniar HS, Schuessler RB, et al. The Cox-maze IV procedure for lone atrial fibrillation: a single center experience in 100 consecutive patients. J Interv Card Electrophysiol. 2011; 31:47-54.

28. Ad N, Henry L, Hunt S. Minimally invasive Cox maze procedure: a single center's experience with 100 consecutive cases. Innovations. 2012;7:129.

29. Ad N, Henry L, Hunt S. Combination of energy sources versus cryothermia alone when performing the Cox maze procedure for ablation of atrial fibrillation. Innovations. 2012;7:12. 